\title{
Review of interferon beta- $l b$ in the treatment of early and relapsing multiple sclerosis
}

\author{
This article was published in the following Dove Press journal: \\ Biologics:Targets \& Therapy \\ 10 July 2009 \\ Number of times this article has been viewed
}

\section{Damiano Paolicelli \\ Vita Direnzo \\ Maria Trojano \\ Department of Neurological and Psychiatric Sciences, University of Bari, Bari, Italy}

Correspondence: Maria Trojano Department of Neurological and Psychiatric Sciences, University of Bari, Policlinico di Bari, Plzza Giulio Cesare, II Zip-code 70I 24, Bari, Italy Tel +39080 5478555

$\mathrm{Fax}+390805478555$

Email mtrojano@neurol.uniba.it

\begin{abstract}
Multiple sclerosis (MS) is the most common autoimmune illness of the central nervous system. For many years the inflammatory manifestations of MS were treated using only corticosteroids. Since the 1990s the results of several clinical trials with immunomodulatory agents have changed the therapeutic approach to this disease. Interferon beta (IFN $\beta$ )-1b represents the pioneer of those therapies. There is growing evidence from clinical trials on relapsing-remitting MS and clinically isolated syndromes suggestive of MS that IFN $\beta$ - 1 b reduces the frequency and severity of relapses and the development of new and active brain lesions as assessed by magnetic resonance imaging. Long-term data suggest a persistent efficacy of IFN $\beta-1 b$ on disease activity and a positive effect in slowing disability worsening. Furthermore a reduction of relapse rate and a slight positive effect on the progression were demonstrated when IFN $\beta-1 b$ was administered to still-active secondary progressive MS. IFN $\beta-1 b$ therapy is well tolerated and relatively free of long-term side effects. In spite of the emergence of new agents for the treatment of MS, IFN $\beta-1 b$ still remains a first-line therapy with a fundamental role in all stages of the disease.
\end{abstract}

Keywords: interferon beta-1b, relapsing-remitting multiple sclerosis, clinically isolated syndromes, efficacy, safety, neutralizing antibodies

\section{Introduction}

Interferon beta (IFN $\beta$ )-1b was the first immunomodulatory therapy approved for the treatment of relapsing-remitting (RR) multiple sclerosis (MS) $)^{1-2}$ and currently is the only IFN $\beta$ licensed for use in secondary progressive (SP) MS. ${ }^{3}$ Moreover, recent studies $^{4-5}$ have defined IFN $\beta$-1b efficacy in treating patients with clinically isolated syndrome (CIS). ${ }^{6}$

In this review we focus on biologic activity, clinical and magnetic resonance imaging (MRI) evidence of efficacy, and safety of IFN $\beta-1 b$ in RRMS and patients with CIS.

\section{Pharmacokinetics and pharmacodynamics of IFN $\beta$ - I b}

Human IFN $\beta-1 b$ (Betaferon ${ }^{\circledR} /$ Betaseron $^{\circledR}$; Bayer HealthCare) is a lyophilized protein produced by DNA recombinant technology by Esecheria coli. As bacteria lack the ability to glycosylate proteins, the recombinant protein was not glycosylated. The cysteine residue at position 17 was replaced with a serine residue to ensure the stability of the molecule and the N-terminal methionine residue was deleted. ${ }^{7}$ It is combined with mannitol and human albumin to reach a neutral $\mathrm{pH}$ of 7.2. 
Assessment of serum IFN $\beta$ concentrations is technically difficult and, thus, the pharmacokinetic characteristics of IFN $\beta-1 b$ are not well described. Lower serum concentrations of IFN $\beta-1 b$ were detected after subcutaneous (SC) compared with intravenous administration, with a relative bioavailability of $51 \%{ }^{8}$ The liver is probably the predominant site of metabolism. ${ }^{9}$

The mechanisms of action of IFN $\beta$ are not yet finally understood, but there is agreement that the major effects are:

- inhibition of T lymphocyte proliferation and decrease of IFN- $\gamma$ production; ${ }^{10}$

- inhibition of major histocompatibility complex class II (MHC II) expression, with reduced antigen presentation within central nervous system (CNS); ${ }^{11}$

- inhibition of matrix metalloproteinase (MMP) production and cell-associated adhesion molecule expression, ${ }^{12-14}$

- induction of anti-inflammatory and inhibition of pro-inflammatory cytokines; ${ }^{15-17}$

- induction of CD8 regulatory cell function and inhibition of monocyte activation. ${ }^{18}$

\section{Pilot dose-finding trials of IFN $\beta$ - I b}

A pilot study ${ }^{19}$ demonstrated that a dose of $250 \mu \mathrm{g}$ of SC IFN $\beta$ - $1 \mathrm{~b}$ increased CD8 cell-mediated suppressor activity in MS patients to levels approaching those in patients without MS. Lower doses showed a lesser effect on CD8 suppressor cell function, suggesting an adequate dosing is important for IFN $\beta-1 \mathrm{~b}$ treatment. In a pilot dose-finding trial of SC IFN $\beta-1 b,{ }^{20} 5$ groups of RRMS, each including 6 patients, were treated with $25,125,250$ or $500 \mu \mathrm{g}$ of IFN $\beta-1 \mathrm{~b}$ or placebo, respectively, 3 times weekly. The dose-finding results (after 24 weeks) showed a dose-related reduction of relapse frequency. However, patients receiving the highest dose of IFN $\beta-1 \mathrm{~b}$ experienced side effects that led to a dose reduction or dropout within a short time-frame. Four of these patients subsequently received the $250 \mu \mathrm{g}$ dose. The 10 patients receiving the $250 \mu \mathrm{g}$ dose of IFN $\beta-1 \mathrm{~b}$, at the end of the study, had a reduced attack frequency compared to the 6 patients receiving placebo. Based on these results, a dose of $250 \mu \mathrm{g}$ of IFN $\beta-1 \mathrm{~b}$ every other day (EOD) was selected for further investigation.

\section{Efficacy of IFN $\beta$ - I b in RRMS}

In 1993 a double-blind, placebo-controlled phase III trial ${ }^{1}$ led to approval of IFN $\beta-1 b$ as the first therapeutic agent for RRMS. It included 372 patients with RRMS who had scores on the Expanded Disability Status Scale (EDSS) $<5.5$ and who had experienced at least two attacks in the previous 2 years.
Patients were randomized to receive placebo, low dosage $(50 \mu \mathrm{g})$ or high dosage $(250 \mu \mathrm{g})$ of SC IFN $\beta$-1b EOD for 2 years. Exacerbation rates (primary endpoint of the study) were significantly lower in both treatment groups compared with the placebo group (high dosage vs placebo $P=0.0001$; low dosage vs placebo $P=0.01$ ) and in high dosage vs low dosage group $(P=0.0086)$, suggesting a dosage effect. The MRI results ${ }^{2}$ supported the clinical results showing a significant reduction of $\mathrm{T} 2$ active scans (high dosage vs placebo $P=0.0089$; low dosage vs placebo $P=0.04$ ), appearance of new T2 lesions (high dosage vs placebo $P=0.0026$; low dosage vs placebo $P=0.03$ ) and MRI burden of disease (high dosage vs placebo $P<0.001$; low dosage vs placebo $P=0.04$ ) in the treatment groups as compared with placebo group. An extension study, lasting up to 5 years, showed that IFN $\beta-1 b$ at dose of SC $250 \mu \mathrm{g}$ EOD continued to have a persistent effect on exacerbation rate reduction $(-33 \%)$ and MRI burden of disease, and was relatively free of longterm side effects. ${ }^{21}$ Moreover a post-hoc analysis showed that the beneficial effect of IFN $\beta-1 b$ on relapse frequency had rapid onset, an effect being observed as early as the second month of treatment. ${ }^{22}$ The increase in MRI lesion burden in the placebo arm was approximately 5 -fold higher than that seen in the higher dose IFN $\beta$-1b group, and even the lower dose reduced MRI lesion burden substantially.

A more recent study ${ }^{23}$ on 30 RRMS patients, followed monthly for a 6-month baseline period and then for a period up to 36 months from the start of treatment with IFN $\beta-1 b$ (SC $250 \mu \mathrm{g}$ EOD), demonstrated a significant effect of the drug in slowing the progression of cerebral atrophy during years 2 and 3 .

To evaluate long-term safety and efficacy of IFN $\beta-1 b$ in RRMS patients, a multicenter, open-label, observational study was conducted up to 16 years of follow-up using crosssectional data collection from patients having participated in the original pivotal trial. ${ }^{24}$ Survival, disease status, relapse rate, EDSS score, adverse events, MRI data were collected. The results were analysed by stratification according to the original assignment of the pivotal trial (placebo, $50 \mu \mathrm{g}$, $250 \mu \mathrm{g}$ of IFN $\beta-1 \mathrm{~b}$ ) and according to the duration of treatment exposition during 16 years of follow-up ( $<20 \%$ of exposition; $20 \%$ to $80 \% ;>80 \%$ ). Eighty-eight percent of the patients from the original trial participated in the long-term follow-up. High adherence to the treatment was evidenced by the median treatment duration of the whole cohort (almost 10 years). The final results of this longer follow-up study suggested that early and continuous long-term treatment with IFN $\beta-1 b$ was favorable for the patients, since relapse 
frequency reduction was similar to the pivotal study $(>40 \%)$, and progression of disability, evaluated at the EDSS score of 6 (unable to walk without assistance), was even slower in patients exposed for a longer period compared to other groups with a shorter period of treatment.

These reported results ${ }^{24}$ were confirmed by a more recently published long-term observational study ${ }^{25}$ showing that IFN- $\beta$ treated patients have a significant reduction in the incidence of secondary progression, EDSS 4.0 and 6.0, compared with untreated patients, during a follow-up lasting up to 7 years.

\section{Efficacy of IFN $\beta$-I $b$ in patients with CIS}

MRI and histological findings demonstrate that irreversible axonal damage begins early in the course of MS. ${ }^{26,27}$ Furthermore, neuropathological findings suggest the potential for immunomodulatory treatment of MS to have a greater effect early in the disease course. ${ }^{28-29}$ Three multicenter, placebo-controlled studies, ${ }^{30-34}$ have shown that IFN $\beta$ treatment delays conversion to clinically definite MS (CDMS) ${ }^{32}$ when administered to patients with CIS (Table 1). However the Betaferon/Betaseron in Newly Emerging Multiple Sclerosis For Initial Treatment (BENEFIT) study ${ }^{4}$ was also designed to assess if early initiation of treatment with IFN $\beta-1 b$ is more efficacious than a delayed treatment for preventing the development of long-term confirmed disability.

Between February 2002 and June 2003, patients with CIS from 18 European countries, Israel, and Canada were randomized in 98 centers. The inclusion criteria were: age between 18 and 45 years, a first clinical neurological event suggestive of MS, at least two clinically silent lesions on their T2-weighted brain MRI scan (at least one of which being ovoid, periventricular, or infratentorial), and EDSS score of 0 to 5 . Study treatment had to be started within 60 days after onset of the first clinical event. Patients were centrally randomized (in a 5:3 ratio) to IFN $\beta-1 b 250 \mu \mathrm{g}$ ( $8 \mathrm{MIU}$ ) or placebo SC EOD and scheduled to receive double-blinded injections for up to 2 years or until CDMS was reached. This first phase ended in 2005 and assessed the efficacy, safety and tolerability of IFN $\beta-1 \mathrm{~b} 250 \mu \mathrm{g}$. After 2 years, $45 \%$ of placebo patients had converted to CDMS (primary outcome measure) and $85 \%$ fulfilled the McDonald criteria (co-primary outcome measure). Overall IFN $\beta-1 \mathrm{~b}$ delayed the time to diagnosis of CDMS $(P<0.0001)$ and McDonald MS $(P<0.00001)$. The risk for CDMS in the IFN $\beta$-1b group was reduced by $50 \%$ and for Mc Donald MS by 46\%. Based on Kaplan-Meier estimates, the probability of the development of CDMS over

Table I Placebo-controlled studies of IFN $\beta$ treatment in patients with clinically isolated syndromes (CIS): comparison of beneficial effects on probability of conversion to clinically definite multiple sclerosis (CDMS) and magnetic resonance imaging measures

\begin{tabular}{|c|c|c|c|c|c|c|c|}
\hline Drug & Study & Study design & $\begin{array}{l}\text { Follow-up } \\
\text { years }\end{array}$ & $\begin{array}{l}\text { No. of } \\
\text { patients }\end{array}$ & $\begin{array}{l}\text { Probability } \\
\text { of conversion } \\
\text { to CDMS (\%) }\end{array}$ & $\begin{array}{l}\text { No. of new or } \\
\text { enlarging lesions }\end{array}$ & No. Gd+ lesions \\
\hline \multirow{5}{*}{$\begin{array}{l}\text { IFN } \beta \text {-Ia } 30 \mu g \text { IM } \\
\left.\text { OW (Avonex }{ }^{\circledR}\right)\end{array}$} & CHAMPS ${ }^{a}(2000)$ & treated vs & 3 years & 383 & 35 vs $50 \%$ & $2.1 \pm 3.2(M \pm S D)$ vs & $0.4 \pm 1.5(\mathrm{M} \pm \mathrm{SD}) \mathrm{vs}$ \\
\hline & & placebo & & & $P=0.002$ & $\begin{array}{l}5.0 \pm 7.7(M \pm S D) \\
P<0.001\end{array}$ & $\begin{array}{l}\mathrm{I} .4+3.6(\mathrm{M} \pm \mathrm{SD}) \\
P<0.00 \mathrm{I}\end{array}$ \\
\hline & CHAMPIONS & early vs & 5 years & 203 & 36 vs $49 \%$ & $3.5(0.5-8.5)$ vs & $>$ I lesions \\
\hline & & delayed & & & $P=0.03$ & $6.0(2.0-13.0)$ & $29 \%$ vs $30 \%$ \\
\hline & & treatment & & & & $P=0.05$ & $P=$ n.s. \\
\hline \multirow{4}{*}{$\begin{array}{l}\text { IFN } \beta \text {-I a } 22 \mu \mathrm{g} \text { SC } \\
\text { OW } \text { (Rebif }^{\circledR} 22 \text { ) }\end{array}$} & ETOMSc $(200 I)$ & treated vs & 2 years & 309 & 34 vs $45 \%$ & $2.0(0.5-4.5)$ & $0.5(0-1)$ (median) vs \\
\hline & & placebo & & & $P=0.047$ & (median) vs & $0(0-I)$ (median) \\
\hline & & & & & & $3.0(1.5-6.25)$ & $P=$ n.s. \\
\hline & & & & & & (median) $P<0.001$ & \\
\hline \multirow{6}{*}{$\begin{array}{l}\text { I IFN } \beta \text { - Ib } \\
250 \mu g \text { SC EOD } \\
\left(\text { Betaferon }^{\circledR}\right)\end{array}$} & BENEFIT $^{d}(2006)$ & treated vs & 2 years & 468 & 25 vs $44 \%$ & $2.9 \pm 4.9(\mathrm{M} \pm \mathrm{SD})$ vs & $1.9 \pm 5.2(\mathrm{M} \pm \mathrm{SD}) \mathrm{vs}$ \\
\hline & & placebo & & & $P<0.0001$ & $4.4 \pm 5.7(M \pm S D)$ & $4.3 \pm 7 . I(M \pm S D)$ \\
\hline & & & & & & $P<0.000$ I & $P<0.0001$ \\
\hline & BENEFIT $^{d}$ (2007) & early vs & 3 years & 418 & 37 vs $51 \%$ & $18(7.0-39.0)$ & $0(0.0-\mathrm{I} .0)$ (median) \\
\hline & & delayed & & & $P=0.001$ & (Median) vs 17 & vs $0(0.0-1.0)$ \\
\hline & & treatment & & & & (8.0-37) (median) n.s. & (median) n.s. \\
\hline
\end{tabular}

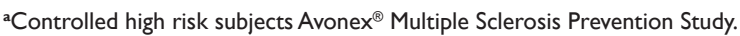

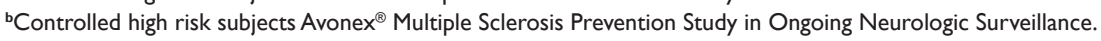

'Early Treatment of Multiple Sclerosis Study.

dBetaferon ${ }^{\circledR} /$ Betaseron $^{\circledR}$ in Newly Emerging Multiple Sclerosis for Initial Treatment.

eBased on Kaplan-Meier life tables.

Abbreviations: EOW, every other week; IM, intramuscular; SC, subcutaneous; OW, once weekly. 
2 years was reduced by treatment from $45 \%$ in the placebo group to $28 \%$ in the IFN $\beta$ - 1 b group corresponding to an absolute risk reduction by $17 \%$. IFN $\beta-1 \mathrm{~b}$ prolonged the time to CDMS by 363 days ( 255 days in the placebo group, 618 days in the IFN $\beta-1 b$ group). The patient number needed to be treated (NNT) in order to prevent one case of CDMS within the study period of 2 years was estimated to be 5.9. Within the first 6 months, the probability to reach MS diagnosis according to the McDonald criteria was $51 \%$ for placebo and $28 \%$ for IFN $\beta$-1b-treated patients. Within 2 years this probability was reduced by treatment from $85 \%$ in the placebo group to $69 \%$ in the IFN $\beta-1 \mathrm{~b}$ group, corresponding to an absolute risk reduction of $16 \%$. There was also a significant treatment effect of IFN $\beta-1 b$ on time to CDMS in all subgroups defined by different baseline characteristics (monofocal or multifocal manifestation, number of T2 lesions $<9$ or $>9$ and absence or presence of at least one gadolinium positive $[\mathrm{Gd}+]$ lesion in the screening MRI). The treatment effect was more pronounced in patient subgroups with less inflammatory disease activity as documented by Gd enhancement or $\mathrm{T} 2$ lesions count and less dissemination in space at the time of the first event. The MRI results ${ }^{33}$ from patients completing 2 years of follow-up demonstrated that IFN $\beta-1 b$ had a robust effect on MRI measures: the cumulative number of new T2 lesions and new $\mathrm{Gd}+$ lesions was $60 \%$ lower in patients receiving IFN $\beta-1 \mathrm{~b}$ vs placebo. A robust treatment effect was found throughout all subgroups defined by clinical and MRI measures of disease activity or dissemination in space at onset. The subgroups analysis reveals a consistently stronger treatment effect in patients with monofocal clinical presentation, fewer $\mathrm{T} 2$ lesions, or not contrast enhancement at baseline, confirming that treatment was particularly beneficial in patients with less active or disseminated disease.

Patients who completed the placebo-controlled phase were eligible to participate to a single-arm (IFN $\beta-1 b$ ) follow-up phase lasting at least 5 years from the period of randomization. ${ }^{5}$ This was prospectively designed to explore the long-term impact of early vs delayed treatment on progression of neurological disability and on brain MRI measures, including outcomes of neurodegeneration such as brain atrophy. Primary outcomes were time to diagnosis of CDMS and time to confirmed EDSS progression. Of the 468 patients originally randomized, 418 (89\%) entered the follow-up phase; 392 (84\%) completed 3 years post-randomization follow-up. After 3 years 99 (37\%) patients in the early group developed CDMS compared with 85 (51\%) patients in the delayed treatment group. ${ }^{6}$ Early treatment reduced the risk of CDMS by $41 \%$ compared with delayed treatment. Over
3 years, $42(16 \%)$ patients in the early group and 40 (24\%) in the delayed group had confirmed EDSS progression; early treatment reduced the risk for progression of disability by $40 \%$ compared with delayed treatment.

Polman at al ${ }^{34}$ evaluated the impact of the demographic, clinical and MRI parameters on the 'natural' risk of MS in placebo-treated patients, and the IFN $\beta-1 \mathrm{~b}$ treatment effect in subgroups of the study population. Four hundred and sixty-eight out of 483 patients from the BENEFIT (IFN $\beta$ - $1 \mathrm{~b}$ : $\mathrm{n}=292$; placebo: $\mathrm{n}=176$ ) were grouped according to demographic, clinical, cerebrospinal fluid (CSF), and MRI findings at disease onset. The 'natural' risk of CDMS over 2 years was estimated by Kaplan-Meier statistics in placebo-treated patients; the IFN $\beta-1 b$ treatment effect was analysed by Cox proportional hazards regression. In the placebo-treated group a higher risk to develop CDMS was found in younger ( $<30$ vs $>30$ years: $60 \%$ vs $33 \%$ ), CSF-positive patients ( $49 \%$ vs $36 \%$ ), in those who had received steroid treatment (48\% vs $38 \%)$ and had $\geq 9$ T2 (48\% vs $39 \%)$ or $\geq 1 \mathrm{Gd}+$ $\mathrm{T} 1$ (52\% vs $41 \%)$ MRI lesions. The CDMS risk was higher (75\%) in placebo-treated patients with monofocal disease onset displaying higher MRI disease activity ( $\geq 1 \mathrm{Gd}+$ lesion) and dissemination ( $\geq 9 \mathrm{~T} 2-$ lesions).

Treatment effects on time to CDMS conversion were significant in all subgroups, with a greater impact on patients with less disease dissemination/activity at onset (monofocal vs multifocal: $55 \%$ vs $37 \%$; $<9$ vs $>9$ MRI T2- lesions: $60 \%$ vs $43 \%$; absence vs presence of MRI Gd+ lesions: $57 \%$ vs $38 \%$ ). Moreover monofocal patients had further greater treatment effects if they had $\geq 9 \mathrm{~T} 2$ - lesions or presence of $\mathrm{Gd}+$ lesions, or both.

\section{Efficacy of IFN $\beta$-I $b$ in SPMS}

Two large placebo-controlled studies of IFN $\beta-1 b$ in SPMS have been conducted: the European study and the North-American study. ${ }^{3,35}$ In both studies, IFN $\beta-1 b 250 \mu \mathrm{g}$ recipients had fewer relapses and less MRI-assessed disease activity than placebo recipients. Only the European trial ${ }^{3}$ provided evidence that the treatment delays the progression of the disease. The conflicting result on the primary endpoint might be explained by differences in the inclusion criteria and baseline characteristics of the study populations. In the European SPMS trial, the patients appeared to be younger, with a shorter duration of disease, faster disease progression and disease characteristics thought to reflect the inflammatory component of the illness, such as higher relapse rates and a greater number of contrast enhancing lesions. These results were supported by a post-hoc analysis of the European SP 
MS trial ${ }^{36}$ in which patients with higher pre-study disease activity ( $>2$ relapses, EDSS progression $>1$ point over the 2 years before study) seemed to have a more favorable treatment effect.

\section{Head-to-head comparative studies of IFN $\beta$-I b}

Low dose IFN $\beta$-1a intramuscular (IM) was compared with high dose IFNB-1b SC in 188 patients of the Independent Comparison of Interferon (INCOMIN) study. ${ }^{37}$ After 2 years the percentage of patients free from relapses and from new $\mathrm{T} 2$ or $\mathrm{Gd}+$ lesions was higher in IFN $\beta-1 \mathrm{~b}$ than in IFN $\beta-1 \mathrm{a}$ group. Patients in high-dose IFN $\beta-1 b$ had a lower risk for confirmed disability progression (EDSS increase of at least one point sustained for at least 6 months and confirmed at the end of follow-up) than those in low-dose IFN $\beta$-1a.

The Betaferon ${ }^{\circledR} /$ Betaseron $^{\circledR}$ Efficacy Yielding Outcomes of a New Dose (BEYOND) study ${ }^{38}$ investigated the effect of two high doses of IFN $\beta-1 \mathrm{~b}$ regimens $(500 \mu \mathrm{g}$ and $250 \mu \mathrm{g} \mathrm{SC}$ EOD) or glatiramer acetate (GA) in RRMS treatment-naïve patients $(\mathrm{N}=2244)$.

Patients with age between 18 and 55 and EDSS in 0 to 5 range were enrolled. There were no significant differences between the two IFN $\beta-1 b$ regimen groups for the primary and secondary clinical (relapse-related measures, progression as assessed by EDSS score) and MRI (new T2 lesions, and volume of $\mathrm{T} 2$ and $\mathrm{Gd}+$ lesions) outcomes. The comparison between IFN $\beta-1 b$ arms and GA arm showed similar treatment effects on clinical endpoints, ${ }^{38-39}$ but a significant superior effect of both IFN $\beta-1 b$ arms on the cumulative number of $\mathrm{T} 2$ lesions up to the last scan and on the relative increase in T2 lesion volume. ${ }^{40}$

A Danish head-to-head, controlled, open-label, randomized study aimed to compare the effects of IFN $\beta-1 \mathrm{~b} 250 \mu \mathrm{g}$ EOD with IFN $\beta-1$ a $22 \mu \mathrm{g}$ once weekly (OW) in RRMS did not prove significant differences on clinical and MRI measures during a period of a follow-up of 2 years. ${ }^{41}$

\section{Clinical relevance of neutralizing antibodies against IFN $\beta$}

During IFN $\beta$ therapy a significant percentage of patients develop neutralizing antibodies to IFN $\beta$ (NAbs).

In the pivotal phase III trial of IFN $\beta-1 b,{ }^{1} 35 \%$ of treated patients developed NAbs to IFN $\beta-1 b$. In this study a sample was considered positive if the NAb titer was at least $20 \mathrm{NU} / \mathrm{mL}$ based on a viral cytopathic effect reduction assay $(\mathrm{CPE})$. NAb positive $(\mathrm{NAb}+)$ patients were the ones with two consecutive positive samples, 3 months apart.
The results from an extensive study aimed to assess the therapeutic impact of $\mathrm{Nabs}^{42}$ suggested a lesser efficacy of IFN $\beta-1 b$ in NAb+ patients with respect to relapse rate reduction, whereas the disease progression in $\mathrm{NAb}+$ patients appeared less marked than in NAb negative (NAb-) patients. Similar results were reported by a number of other short-term trials, ${ }^{43-46}$ demonstrating that patients who develop NAbs to both IFN $\beta-1 \mathrm{~b}$ and $1 \mathrm{a}$ were associated with higher relapse rates and lesion activity on MRI, but without relevant effect on disability progression.

A longer-term follow-up ${ }^{47}$ of two cohorts from the original pivotal IFN $\beta-1 b$ trial provided further data on the development of NAbs showing their transient nature. Moreover this study demonstrated that $91 \%$ of NAb+ patients reverted to $\mathrm{NAb}$ - status after 8 years of treatment. A longitudinal study ${ }^{48}$ confirmed that high titres of NAbs suppress the relapsereducing efficacy of IFN $\beta$. However since a gradual reduction in titres appeared and NAbs frequently became undetectable with the continuation of the therapy, extending the medication resulted in full return of efficacy for the $20 \%$ of patients for whom the appearance of NAbs was clinically significant. Sorensen et al ${ }^{49}$ evaluated the clinical relevance of NAbs in 541 RRMS who started treatment with IFN $\beta$ between 1996 and 1999 in Denmark. The results showed that relapse rates were significantly $(P<0.03)$ higher during NAb+ periods $(0.64$ to 0.70 ) than they were during NAb- periods $(0.43$ to 0.46$)$. Time to first relapse was significantly increased by 244 days in patients who were NAB-at 12 months (log rank test 6.83, $P=0.009$ ). During a follow-up period of 60 months, the presence of NAbs did not affect significantly the disability progression as measured by time to confirmed progression of 1 point on EDSS, sustained for at least 6 months.

The INCOMIN study ${ }^{37}$ showed a greater frequency of $\mathrm{NAb}+$ patients in the group treated with high-dose IFN $\beta-1 b$ $\mathrm{SC}$ in comparison to those treated with low-dose IFN $\beta-1 \mathrm{a}$ IM, in spite of better clinical and MRI outcome.

In a more recent prospective, multicenter, observational study by the same authors, ${ }^{50} \mathrm{MRI}$ activity and NAb positivity (assessed by $\mathrm{M} \times \mathrm{A}$ protein assay) in the first 6 months of IFN $\beta$ treatment resulted predictors of long term clinical response (occurrence of one or more relapses or confirmed disease progression), particularly when combined. Patients with negative predictors showed less than $10 \%$ risk of developing clinical activity, while patients with positive predictors showed a 50\% risk of further clinical activity. Similar conclusions were reached by another group in patients treated with IFN $\beta-1$ a or IFN $\beta-1 b$, measuring the IFN $\beta$ bioavailability marker mRNA $M \times A .{ }^{51}$ 
In CIS patients included in the BENEFIT study the incidence of positive NAb titers ranged from $16.5 \%$ to $25.2 \%$ of the treated patients. ${ }^{4}$ Neutralizing activity was detected at least once in 75 out of 251 (29.9\%) IFN $\beta-1 b$ patients who provided samples during the treatment phase; of these, $17(22.7 \%)$ converted to negative status later in the study. No significant effect of NAb status on time to CDMS in IFN $\beta-1 b$ treated patients was found; in this analysis there was a trend toward a lower risk of progressing to CDMS in patients with at least one positive NAb titer. When analyses were performed at the end of the study (at least 180, 270 or 360 days after start of treatment) no differences were observed between $\mathrm{NAb}+$ and $\mathrm{Nab}-$ patients.

The clinical impact of NAbs on treatment efficacy in 6698 MS patients receiving IFN $\beta-1 \mathrm{~b}$ was investigated by Goodin et al ${ }^{52}$ suggesting that NAbs are not responsible for poor clinical responses and NAb status is of little clinical value.

In conclusion the results derived from existing studies are conflicting and have to be interpreted with caution. The differences might be due to the different duration of follow-up, assays and definitions of NAb positivity used. The impact of NAbs seems to be more frequently evident on proper inflammatory clinical events of MS (relapse rate) but the influence of NAbs on the progression of the disease remains uncertain. Therefore the decisions to discontinue IFN $\beta$ therapy are still based mainly on the patient's clinical response to the treatment.

\section{IFN $\beta$-I $b$ and adverse events}

The administration of IFN $\beta$ is associated with the risk of a variety of adverse effects ${ }^{53,54}$ The most common, compared with placebo, are flu-like symptoms and, in SC-treated patients, injection-site reactions.$^{53}$ In the pivotal IFN $\beta-1 \mathrm{~b}$ trial, ${ }^{1}$ flu-like symptoms in the high-dose group were initially observed in $52 \%$ of patients. However, by the end of the first year, these had decreased to $8 \%$, only $3 \%$ to $8 \%$ of patients experiencing symptoms throughout the study. Injection-site reactions in the same pivotal trial were initially reported by $80 \%$ of those receiving $250 \mu \mathrm{g}$ IFN $\beta-1 \mathrm{~b}$, a figure that declined to between $44 \%$ and $50 \%$ at years 4 and 5 .

During the first year of the BEYOND study, ${ }^{55}$ flu-like symptoms were reported significantly more frequently in the IFN $\beta-1 b 250 \mu$ g group compared to the GA group. Although initially high, the frequency of flu-like symptoms in IFN $\beta$ treated group declined very quickly over time. For injection-site reactions, pain and pruritus were significantly more frequent in the GA treatment group than in the IFN $\beta-1 \mathrm{~b} 250 \mu \mathrm{g}$ group, but in the same way, the incidence of this reactions decreased over the study. The incidence of other adverse events such as fatigue, depression, arthralgia and paresthesia was comparable between treatments groups. The evaluation of laboratory safety as elevations in liver enzymes abnormalities, in blood lipids and markers of thyroid function, as well as leukocytopenia were more frequently detected in patients treated with IFN $\beta-1 b$ than in those treated with GA. Adherence to treatment was also assessed demonstrating that the adherence to treatment was high in all three treatment groups. ${ }^{56,57}$ The proportion of patients completing the anticipated treatment period ranged from $73 \%$ in the IFN $\beta-1 b 500 \mu$ g group through $78 \%$ in GA group to $82 \%$ in the IFN $\beta-1 \mathrm{~b} 250 \mu \mathrm{g}$ group. No significant differences in discontinuation rates were observed among the groups.

The management of IFN $\beta$-related side effects is of great importance to improve the patients's treatment adherence. General precautions to reduce or avoid this side effect include the correct preparation of the injection solution and a proper injection technique. In all studies frequency and severity of adverse effects depend on the duration of treatment and they are at a maximum during the first weeks of treatment.

\section{Conclusions}

Results from rationally planned and statistically convincing studies in RRMS and CIS patients demonstrated that IFN $\beta-1 b$ treatment has very favorable efficacy on clinical and MRI measures of disease activity and progression since very early stages of disease.

Early and continuous treatment with IFN $\beta-1 b$ maintains persistent effectiveness and safety in the long term. A reduction in attack rate and a slight positive effect on the progression of disability were also demonstrated when IFN $\beta-1 b$ was administered to patients in SP phase. Therefore IFN $\beta-1 b$ still represents a key therapeutic option for MS patients, playing a fundamental role in all stages of the disease. No definitive relationship between development of NAbs and response to treatment has been demonstrated.

\section{Disclosures}

DP and VD declare no conflicts of interest. MT has received honoraria for speaking from Sanofi-Aventis, Biogen and Bayer Schering, and research grants from Merck Serono. 


\section{References}

1. IFNB Multiple Sclerosis Study Group. Interferon beta- $1 \mathrm{~b}$ is effective in relapsing-remitting multiple sclerosis. I. Clinical results of a multicenter, randomized, double-blind, placebo-controlled trial. Neurology. 1993;43:655-661.

2. Paty DW, Li DK. Interferon beta- $1 \mathrm{~b}$ is effective in relapsing remitting multiple sclerosis. II.MRI analysis results of a multicenter, randomized, double blind, placebo controlled trial. UBC MS/MRI Study Group and The IFN beta multiple sclerosis study group. Neurology. 1993;43:662-667.

3. European Study Group on Interferon beta-1b in secondary progressive MS. Placebo-controlled multicentre randomised trial of interferon beta- $1 \mathrm{~b}$ in treatment of secondary progressive MS. Lancet. 1998;352:1491-1497.

4. Kappos L, Polman CH, Freedman MS, et al. Treatment with interferon beta-1b delays conversion to clinically definite and McDonald MS in patients with clinically isolated syndromes. Neurology. 2006;67: 1242-1249.

5. Kappos L, Freedman MS, Polman CH, et al. BENEFIT Study Group. Effect of early vs delayed interferon beta-1b treatment on disability after a first clinical event suggestive of multiple sclerosis: a 3-year follow-up analysis of the BENEFIT study. Lancet. 2007;370:89-97.

6. Polman C, Reingold S, Edan G, et al. Diagnostic criteria for Multiple Sclerosis: 2005 Revisions to the "McDonald Criteria". Ann Neurol. 2005;58:840-846.

7. Mark DF, Lu SD, Creasey AA, Yamamoto R, Lin LS. Site-specific mutagenesis of the human fibroblast interferon gene. Proc Natl Acad Sci US A. 1984;81:5662-5666.

8. Chiang J, Gloff CA, Yoshizawa CN, Williams GJ. Pharmacokinetics of recombinant interferon-beta ser in healthy volunteers and its effect on serum neopterin. Pharm Res. 1993;10:567-572.

9. Wills RJ. Clinical pharmacokinetics of interferons. Clin Pharmacokinet. 1990;19:390-399.

10. Noronha A, Toscas A, Jensen MA. Interferon beta decreases $\mathrm{T}$ cell activation and interferon gamma production in multiple sclerosis. J Neuroimmunol. 1993;46:145-153.

11. Lu HT, Riley JL, Babcock GT, et al. Interferon (IFN) beta acts downstream of IFN-gamma-induced class II transactivator messenger RNA accumulation to block major histocompatibility complex class II gene expression and requires the 48-kd DNA-binding protein, ISGF3-gamma. J Exp Med. 1995;182:1517-1525.

12. Leppert D, Waubant E, Burk MR, Oksenbert JR, Hauser SL. Interferon beta-1b inhibits gelatinase secretion and in vitro migration of human T cells: a possible mechanism for treatment efficacy in multiple sclerosis. Ann Neurol. 1996;40:846-852.

13. Stuve O, Dooley NP, Uhm JH, et al. Interferon beta-1b decreases the migration of $\mathrm{T}$ lymphocytes in vitro: effects on matrix metalloproteinase-9. Ann Neurol. 1996;40:853-863.

14. Calabresi PA, Tranquill LR, Dambrosia JM, et al. Increases in soluble VCAM-1 correlate with a decrease in MRI lesions in multiple sclerosis treated with interferon beta-1b. Ann Neurol. 1997;41:669-674.

15. Rudick RA, Ransohoff RM, Lee JC, et al. In vivo effects of interferon beta-1a on immunosuppressive cytokines in multiple sclerosis. Neurology. 1998;50:1294-1300.

16. Rep MHG, Hintzen RQ, Polman CH, van Lier RAW. Recombinant interferon-beta blocks proliferation but enhances interleukin-10 secretion by activated human T-cells. J Neuroimmunol. 1996;67:111-118.

17. Sega S, Wraber B, Mesec A, Horvat A, Ihan A. IFN-beta 1a and IFNbeta $1 \mathrm{~b}$ have different patterns of influence on cytokines. Clin Neurol Neurosurg. 2004;106:255-258.

18. Noronha A, Toscas A, Arnason BG, Jensen MA. Interferon beta augments suppressor cell function in multiple sclerosis. Ann Neurol. 1990;27:207-210.

19. Noronha A, Toscas A, Arnason BG, Jensen MA. IFN beta augments in vivo suppressor function in MS. Neurology. 1994;44 Supp1 2:A212.

20. Knobler RL, Greenstein JI, Johnson KP, et al. Systemic Recombinant Human Interferon beta treatment of relapsing remitting multiple sclerosis: pilot study analysis and six-year follow up. J Interferon Res. 1993;13:333-340.
21. IFNB Multiple Sclerosis Study Group and the University of British Columbia. MS/MRI Analysis Group. Interferon beta- $1 \mathrm{~b}$ in the treatment of multiple sclerosis: final outcome of the randomized controlled trial. Neurology. 1995;45:1277-1285.

22. Arnason BG, for the IFNB Multiple Sclerosis Study Group and the UBC MS/MRI Analysis Group High dose, high frequency interferon beta-1b (Betaferon/Betaseron) treatment is effective in early stage relapsing remitting multiple sclerosis. Neurology. 2003;60 Suppl 1:A481.

23. Frank JA, Richert N, Bash C, et al. Interferon-beta-1b slows progression of atrophy in RRMS: Three-year follow-up in NAb-and NAb+ patients. Neurology. 2004;62:719-725.

24. Ebers G, Traboulsee A, Langdon D, and the LTF Study Group. The interferon beta-1b 16-year long-term follow-up study: the results. Neurology. 2006; suppl AAN 58th Meeting San Diego, CA A32 Po1. 079.

25. Trojano M, Pellegrini F, Fuiani A, et al. New natural history of interferon beta- treated relapsing multiple sclerosis. Ann Neurol. 2007; 61:300-306.

26. De Stefano N, Narayanan S, Francis GS, et al. Evidence of axonal damage in the early stages of multiple sclerosis and its relevance to disability. Arch Neurol. 2001;58:65-70.

27. Kuhlmann T, Lingfeld G, Bitsch A, Schuchardt J, Bruck W. Acute axonal damage in multiple sclerosis is most extensive in early disease stages and decreases over time. Brain. 2002;125:2202-2212.

28. Barnett MH, Prineas JW. Relapsing and remitting multiple sclerosis: pathology of the newly forming lesion. Ann Neurol. 2004;55: 458-68.

29. Trapp BD, Peterson J, Ransoho RM, Rudick R, Mork S, Bo L. Axonal transection in the lesions of multiple sclerosis. $N$ Engl J Med. 1998;338:278-285.

30. Jacobs LD, Beck RW, Simon JH, et al. Intramuscular interferon beta-1a therapy initiated during a first demyelinating event in multiple sclerosis. CHAMPS Study Group. N Engl J Med. 2000;343:898-904.

31. Comi G, Filippi M, Barkhof F, et al. Effect of early interferon treatment on conversion to definite multple sclerosis: a randomized study. Lancet. 2001;357:1576-1582.

32. Poser CM, Paty DW, Scheinberg L, et al. New diagnostic criteria for multiple sclerosis: guidelines for research protocols. Ann Neurol. 1983;13:227-231.

33. Barkhof F, Polman CH, Radue EW, et al. Magnetic resonance imaging effects of interferon beta-1b in the BENEFIT study: integrated 2-year results. Arch Neurol. 2007;64:1292-1298.

34. Polman C, Kappos L, Freedman MS, et al. BENEFIT investigators. Subgroups of the BENEFIT study: risk of developing MS and treatment effect of interferon beta-1b. J Neurol. 2008;255:480-487.

35. Goodkin DE and the North American SP MS Study Group. Interferon beta-1b in secondary progressive MS: clinical and MRI results of a 3 year randomized controlled trial [abstract]. Neurology. 2000; $54: 2352$.

36. Kappos L, Polman C, Pozzilli C, Thomson A, Beckmann K, Dahlke F. Final analysis of the European multicenter trial of IFNbeta-1b in secondary progressive MS. Neurology. 2001;57:1969-1975.

37. Durelli L, Verdun E, Barbero $\mathrm{P}$, et al; Independent Comparison of Interferon (INCOMIN) Trial Study Group. Every-other-day interferon beta-1b vs once-weekly interferon beta-1a for multiple sclerosis: results of a 2-year prospective randomised multicenter study. Lancet. 2002;27:1453-1460.

38. O'Connor P, Arnason B, Comi G, et al. Interferon beta-1b $500 \mathrm{mcg}$, interferon beta-1b $250 \mathrm{mcg}$ and glatiramer acetate: primary outcomes of the BEYOND. (Betaferon/Betaseron Efficacy Yielding Outcomes of New Dose) study. Neurology. 2008;70(11; Late Breaking Science Suppl):S004.

39. Kappos L, Arnason B, Comi G, et al. High proportion of patients free from disease activity in all 3 arms of the high-dose Betaferon trial. J Neurol. 2008;255 Suppl 2:36.

40. Filippi M, Arnason B, Comi G, et al. Magnetic resonance imaging findings of a phase III trial comparing Betaferon with Copaxone treatments in relapsing-remitting multiple sclerosis. J Neurol. 2008; 255 Suppl 2:9. 
41. Koch-Henriksen N, Sørensen PS, Christensen T, et al; Danish Multiple Sclerosis Group. A randomized study of two interferon-beta treatments in relapsing-remitting multiple sclerosis. Neurology. 2006;66:1056-1060.

42. IFNB Multiple Sclerosis Study Group and The University of British Columbia MS/MRI Analysis Group. Neutralizing antibodies during treatment of multiple sclerosis with interferon beta-1b: experience during the first three years. Neurology. 1996;47:889-894.

43. The IFNB Multiple Sclerosis Study Group I. Neutralizing antibodies during treatment of multiple sclerosis with interferon beta-1b: experience during the first three years. Neurology. 1996;47:889-894.

44. The PRISMS Study Group. Interferon neutralizing antibodies reduce clinical and magnetic resonance efficacy in multiple sclerosis patients treated with IFN $\beta$-1a (Rebif): observations from the PRISMS 4-year extension study (abstract). Ann Neurol. 2000;48:477.

45. Polman CH, Kappos L, White R, et al. Neutralizing antibodies during treatment of secondary progressive MS with interferon $\beta-1 \mathrm{~b}$. Neurology. 2003;60:37-43.

46. Kappos L, Clanet M, Sndberg-Wollheim, the European Interferon Beta-1a IM dose-Comparison Study investigators, et al. Neutralizing antibodies and efficacy in interferon $\beta$-1a: a 4 year controlled study. Neurology. 2005;65:40-47.

47. Rice GP, Paszner B, Oger J, Lesaux J, Paty D, Ebers G. The evolution of neutralizing antibodies in multiple sclerosis patients treated with interferon beta-1b. Neurology. 1999;52:1277-1279.

48. Petkau AJ, White RA, Ebers GC, et al. IFNB Multiple Sclerosis Study Group. Longitudinal analyses of the effects of neutralizing antibodies on interferon beta-1b in relapsing-remitting multiple sclerosis. Mult Scler. 2004;10:126-138.
49. Sorensen PS, Ross C, Clemmesen KM, Bendtzen K, Frederiksen JL, et al. Clinical importance of neutralising antibodies against interferon beta in patients with relapsing remitting multiple sclerosis. Lancet. 2003;362:1184-1191.

50. Durelli L, Barbero P, Bergui M, et al. MRI activity and neutralising antibody as predictors of response to interferon beta treatment in multiple sclerosis. J Neurol Neurosurg Psychiatry. 2008;79: 646-651.

51. Malucchi S, Gilli F, Caldano M, et al. A Predictive markers for response to interferon therapy in patients with multiple sclerosis. Neurology. 2008;70:1119-1127.

52. Goodin DS, Hurwitz B and Noronha A. Neutralizing antibodies to interferon $\beta$-1b are not associated with disease worsening in multiple sclerosis. J Int Med Res. 2007;35:173-187.

53. Bayas A, Rieckmann P. Managing the adverse effects of interferon beta therapy in multiple sclerosis. Drug Saf. 2000;22:149-1594.

54. Walther EU, Hohlfeld R. Multiple sclerosis: side effects of interferon beta therapy and their management. Neurology. 1999;53: $1622-1627$

55. Hartung HP. Early treatment and dose optimisation BENEFIT and BEYOND. J Neurol. 2005;252 Suppl 3:44-50.

56. Comi G, Arnason B, Cook S, et al. Tolerability and adherence to Betaferon and Copaxone in a phase III clinical trial. J Neurol. 2008; 255 Suppl 2:111.

57. Achiron A, Fredrikson S. Lesson from randomised direct comparative trials. J Neurol Sci. 2009; 277 Suppl 1:S19-S24.
Biologics: Targets \& Therapy

\section{Publish your work in this journal}

Biologics: Targets \& Therapy is an international, peer-reviewed journal focusing on the patho-physiological rationale for and clinical application of Biologic agents in the management of autoimmune diseases, cancers or other pathologies where a molecular target can be identified. This journal is indexed on PubMed Central, CAS,

\section{Dovepress}

EMBase, Scopus and the Elsevier Bibliographic databases. The manuscript management system is completely online and includes a very quick and fair peer-review system, which is all easy to use. Visit http://www.dovepress.com/testimonials.php to read real quotes from published authors. 